\title{
DESIGN AND IMPLEMENTATION OF DIGITALLY CONTROLLED PHOTOVOLTAIC MAXIMUM POWER TRACKING SYSTEM
}

\author{
Adel A. Abosnina* \\ and \\ Mahmoud Shaker** \\ *Higher Institute Of Electricity-Benghazi-Libya, adelbu2002@yahoo.com \\ ** Department of Electrical and Electronic Engineering, University of Garyounis, \\ Benghazi-Libya, Mahmoud111957@garyounis.edu
}

\begin{abstract}
In this paper, the design of controller that realizes the operation of PV panel at its maximum power point tracker by means of microcomputer- based Maximum Power Point Tracker, MPPT, and then examines the efficiency of system controller. The maximum power point tracker system used consists mainly of solar panel source, DC/DC converter (load conditioner), the microcomputer proceeds the data and execute the MPPT algorithm, the data acquisition or acquires the real current and voltage from the panel, and the load. The over all system operation is implemented practically using the most popular three control algorithms (Perturbation and Observation, Incremental Conductance., and Power derivation), and the obtained results demonstrate the reliability of the control system.

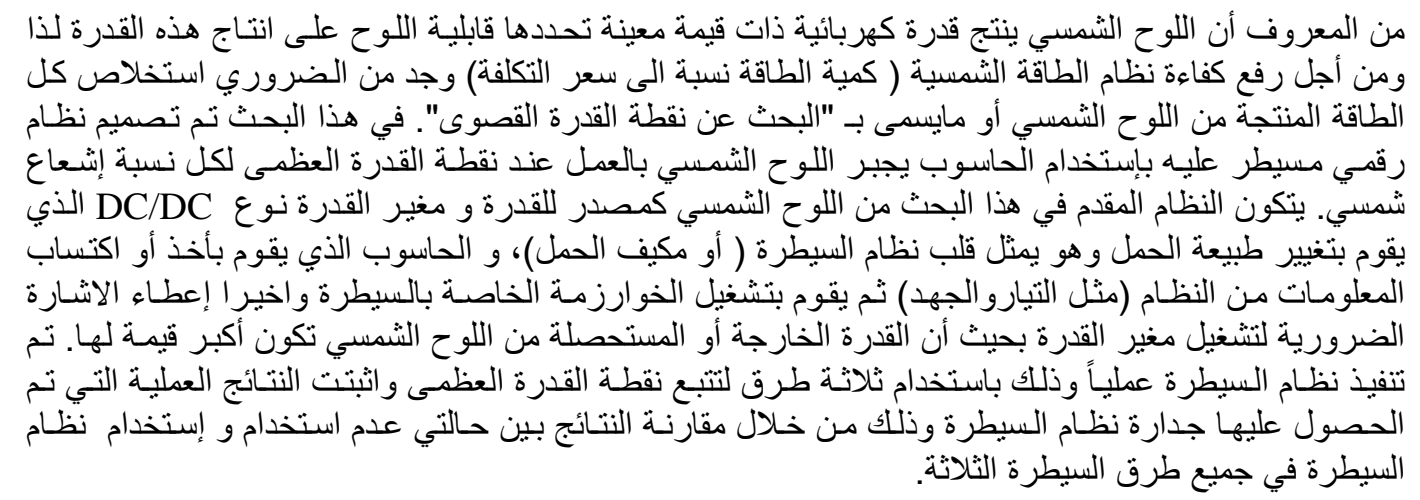

Keywords: PV panel, MPPT, Digital control MPPT, DC/DC converter

\section{INTRODUCTION}

The energy extracted from a solar panel is strongly limited by the physical constraints of photovoltaic cells. The approximate power density of the insulation on a sunny day is around $1000 \mathrm{~W} / \mathrm{m}^{2}$. In combination with solar cell efficiencies between $15 \%$ and $17 \%$ this yields a maximum possible power output between $150 \mathrm{~W} / \mathrm{m}^{2}$ and $170 \mathrm{~W} / \mathrm{m}^{2}$. There are two ways to increase the power coming from a photovoltaic array: One can add more panels to the array, which means an increase in area requirements and a great increase in cost for material. One can also attempt to make the existing array always work at its highest possible efficiency [1]. Since the PV panel generates an electrical power so it is logically to extract all the power generated in order to minimize the cost of PV system.

Maximum power point tracking (MPPT) is an electronic system that operates the photovoltaic (PV) modules or panels in a manner that allows the modules or panels to produce the maximum power they are capable of.
MPPT is not a mechanical tracking system that the modules or panels to make them point more directly at the sun. MPPT is a fully electronic system that varies the electrical operating point of the modules or panels so that the modules or panels are able to deliver maximum available power. MPPT can be used in conjunction with a mechanical tracking system, but the two systems are completely different. The MPPT is required to make sure that the system operates close to the maximum power point (MPP) when it's subjected to changing environmental conditions, Provide high conversion efficiency, maintain tracking for a wide variation in environmental conditions, and Provide an output interface capable with the battery charging requirements. The main target of this paper which is realization of the controller that force the solar panel to operate at its maximum power point (MPPT), three methods will be presented during the paper namely: Perturbation and Observation, incremental conductance, and power derivation algorithms. 


\section{METHODS OF MPPT}

There are many different approaches to extract the maximum possible power out of the P.V. generator. Some of the concepts are very robust and simple, whereas other approaches require very sophisticated logic devices such as microprocessors combined with high-power high-efficiency switching converters.

There are a number of Maximum Power Point Tracking (MPPT) techniques. All of these methods require an algorithm to specify the location of the operating point with respect to the maximum power point. Some of them deliver only a sub-optimum power output. A good MPPT technique should produce a high efficiency at low cost because PV systems will have to be mass-produced. These methods can be classified as indirect methods or direct methods.

\subsection{Indirect Methods}

Indirect methods are those which use an outside signal to estimate the MPP. Such outside signals are derived by measuring the irradiance, the module temperature, the short circuit current, or the open circuit voltage of a reference cell.

A set of physical parameters has to be given, and the MPP set point is derived from the monitored signal. Derived set point on basis of design parameters, operational parameters, or system characteristics [2].

\subsection{Direct Methods}

Direct methods, are those which depend on direct measurements of the solar panel. Algorithms in this category are usually based on the measurement of the DC input current and voltage.

Different algorithms were implemented to detect or track the MPP using the measured values by digital signal processor or by analog circuits, refer to references [1 to 8]. Adjustment of MPP may occur continuously or intermittently. Many direct methods exit in literature such as simple panel-load matching, Voltage control method, Power control method, and Current control method.

\section{EXPERIMENTAL WORK}

\subsection{System Overview}

As known, in most cases when the load is connected directly to the P.V. panel output, the power extracted from the panel is not the maximum value. The extraction of maximum power from P.V. can be obtained by means of a load conditioner situated between the P.V. and the load, the aim of this conditioner (DC/DC converter) is to force the P.V. panel to operate at its maximum power point (MPP) and then a maximum power can be extracted.

The heart of the above point is to control the operation of the DC/DC converter according to the measured values of P.V. current and voltage, and an algorithm (program) that processes the measured data and determines finally the control signal necessary for the adequate operation of DC/DC converter.

Referring to Fig. 1, the maximum power point tracking system consists of the following subsystem:-

1. A PV panel (Type: LG250-12).

2. Sensing circuits (voltage and current).

3. Load conditioner (DC/DC booster)

4. The controller, that can be divided into:

- Data acquisition.

- MPPT algorithm manipulation.

- D/A converter.

- Driving circuit.

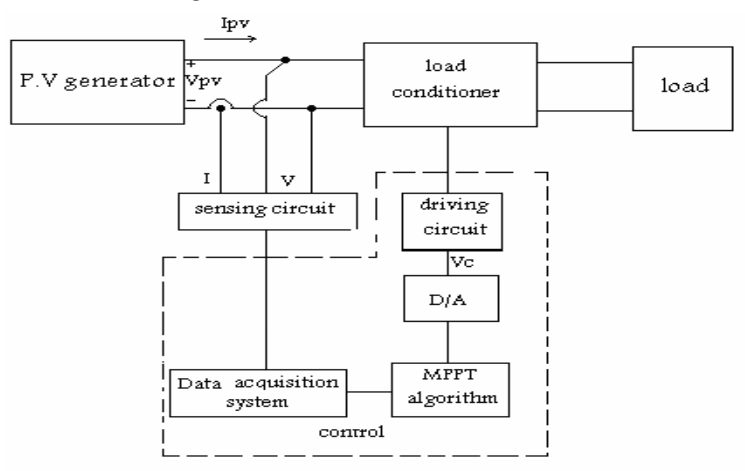

Fig. 1. Block diagram of MPPT system

\subsection{Model of PV and Model Verification}

Modeling of a panel is very important issue, since a model can be used for performance study, analysis, and prediction of the system response prior to its practical implementation. This model is used to investigate the variation of maximum power point with temperature and insulation levels.

A solar cell is usually presented by an electrical equivalent one- diode model, as shown in Fig. 2. The model included temperature dependence of photocurrent, $I_{p h}$, and the saturation current, $I_{s}$, of the diode. A series resistance $\mathrm{R}_{\mathrm{s}}$ was included, but not a shunt resistance.

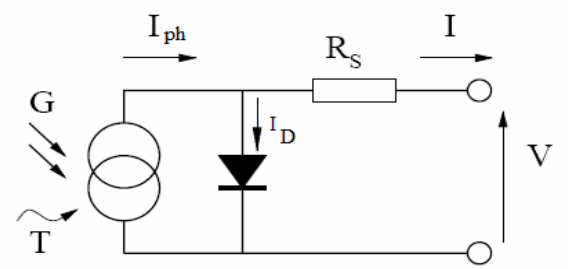

Fig. 2. The circuit diagram of the PV model

The P.V. panel used in this paper is the LG250-12; consist of six modules connected in series. Each of these modules has 36 single crystal silicon solar cells connected in series. It can generate maximum current $2.35 \mathrm{~A}$ and a voltage of $16.6 \mathrm{~V}$ and each module give rise to a maximum power of $39 \mathrm{w}$. Figure 3 shows a photograph of the panel while table (1) presents the specifications of one module [9]. 


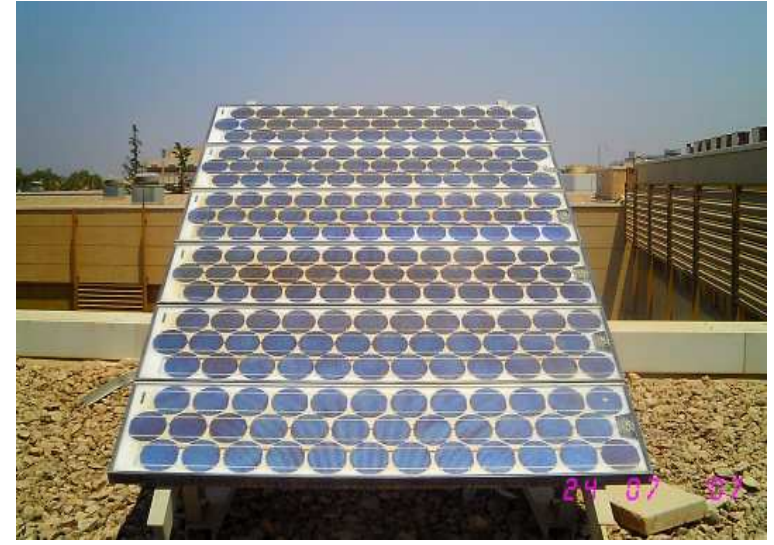

Fig. 3. Photograph of LG250-12 panel

The method of parameter extraction and model evaluation in MatLab is demonstrated. The panel used in this paper is given by equation (1), (refer to reference [10] ).

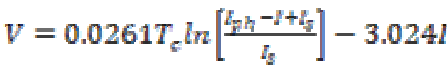

Where:

$$
\begin{aligned}
& I_{p n_{2}}=2.55 \times 10^{-3} G\left[1+K_{o}\left(T_{c}-T_{1}\right)\right] \\
& I_{g}=8.065 \times 10^{-15}\left(T_{c}\right)^{3} \exp \left[-31.112\left(\frac{T_{1}}{T_{c}}-1\right)\right]
\end{aligned}
$$

Table 1, LG-250-12 module specifications

\begin{tabular}{|l|c|c|c|}
\hline \multicolumn{1}{|c|}{ Patameter } & symbol & Nominal value & units \\
Reference temperature & $T_{r f}$ & 25 & $\mathrm{C}^{\circ}$ \\
Open circuit voltage & $V_{s e}$ & 21.11 & $\mathrm{~V}$ \\
\hline Short circuit current & $I_{s \varepsilon}$ & 2.55 & $\mathrm{~A}$ \\
Voltage at max imum power & $V_{s}$ & 16.6 & $\mathrm{~V}$ \\
\hline Current at maximum power & $I_{m}$ & 2.35 & $\mathrm{~A}$ \\
Maximum power & $P_{m}$ & 39 & $\mathrm{~W}$ \\
Number of series cells & $N_{s}$ & 36 & \\
\hline Ideality factor & $n$ & 1.4 & \\
Solar intensity at st. cond. & $G$ & 1000 & $\mathrm{~W} / \mathrm{m}^{2}$ \\
Short circuit temp. coefficient & $K_{o}$ & $0.05 \times 10^{-3}$ & \\
\hline \hline
\end{tabular}

In order to obtain a fair model its necessary the comparison between the experimental and simulation results for the same conditions. Figure 4 represent the experimental and simulation results for the case of $\mathrm{G}=897.67 \mathrm{w} / \mathrm{m}^{2}$ and $\mathrm{T}_{\mathrm{a}}=32 \mathrm{c}^{\circ}$ of PV panel.

\subsection{Design of Chopper}

The most critical section of the power tracker is the switching converter section. The converter force the P.V panel to operate at its maximum efficient point while converting the energy provided up to a voltage that is can be used by the rest of the system. It is also in this section that optimal component choice is important. Since all the panel energy flows through the converter, any resistance or loss will contribute to the power loss of the system. The circuit of this converter is shown in Fig. 5.

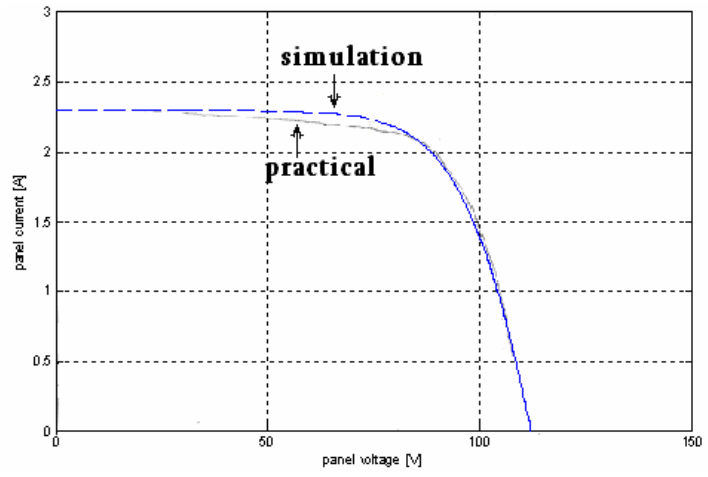

Fig. 4. Simulation and practical $I-V$ curves (PV Panel) for $\mathrm{G}=897.67 \mathrm{~W} / \mathrm{m}^{2}$ and $\mathrm{T}_{\mathrm{a}}=32^{\circ} \mathrm{C}$

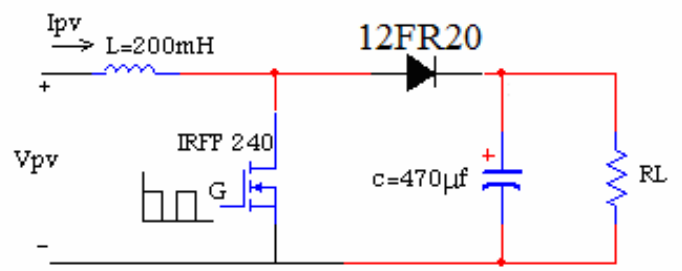

Fig. 5. DC/DC boost converter

The required elements for the boost converter are: MOSFET transistor, inductor, capacitor, and diode. An n-channel enhancement mode power MOSFET IRFP240 is selected as a high speed switching device for the boost converter, the value of inductor and capacitor are $200 \mathrm{mh}$ and $470 \mu \mathrm{f}$ respectively, and a diode 12FR20 [9].

\subsection{System Software}

With the hardware circuit design completed, the next step is the software interpolation of the MPPT algorithm and control of the hardware for the data acquisition and output. During the realization of the presented paper, three algorithms were executed, these are:

\subsubsection{Perturbation and Observation Method (P\&O).}

The P \& O method is widely used in MPPT, because it has a fewer measured parameters. It can track maximum power point quite accurately through variations in radiation and temperature. It operates by perturbing the system by increasing or decreasing the panel operating voltage and observing the impact of this change on the panel output power. Figure 6 is a flow chart of the P\&O algorithm. As shown in Fig. 7, if output power has increased, panel voltage is adjusted in the same direction as in the previous cycle. If the output power had decreased, panel voltage is perturbed in the opposite direction as in the previous cycle. When the maximum power point (MPP) is reached, the output voltage will oscillate around the maximum operation voltage. 


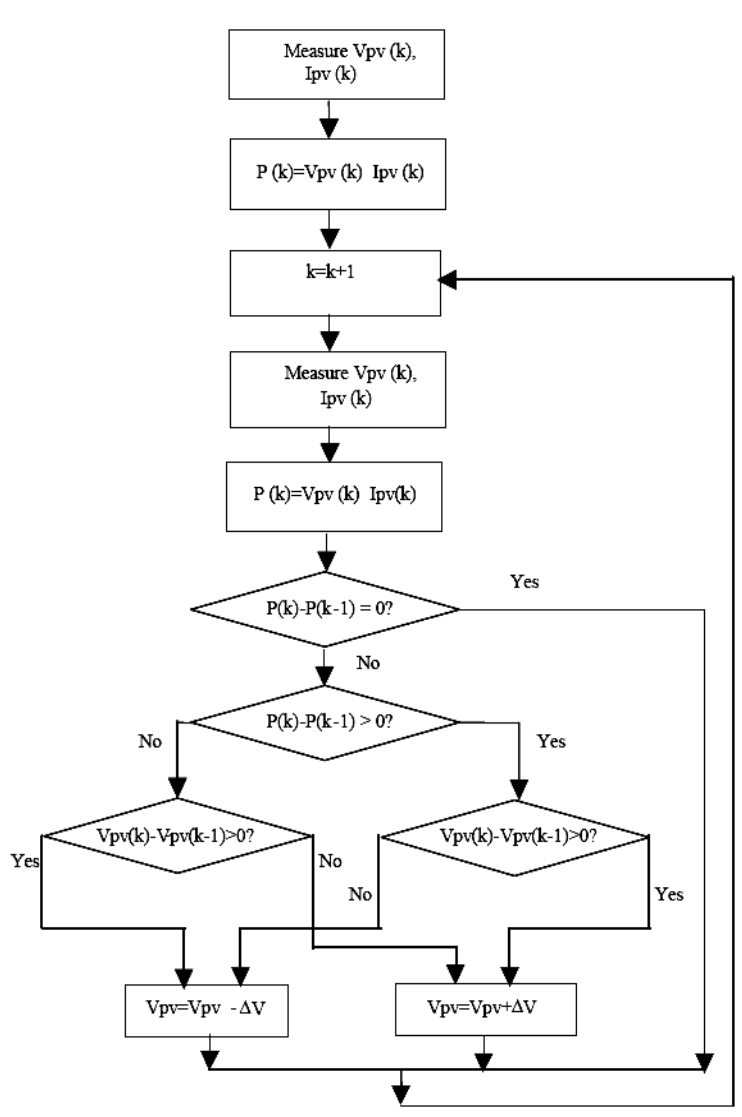

Fig. 6. Flow chart of $\mathrm{P} \& \mathrm{O}$ algorithm

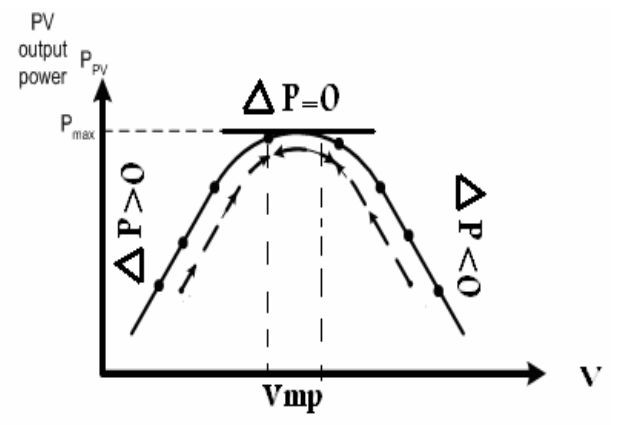

Fig. 7. P-V characteristic of PV panel

\subsubsection{Incremental Conductance Method (Inc.Con).}

The Incremental Conductance method has been proposed to avoid the drawbacks of the P\&O MPPT method. It is based on the fact that the derivative of the output power with respect to the panel voltage is equal to zero at maximum power point. The output voltage and current from the PV panel are monitored upon which the MPPT controller relies to calculate the conductance and incremental conductance, and to make its decision (to increase or decrease duty ratio output). From the PV characteristic of PV panel that shown in Fig. 8. The derivative is positive to the left of the maximum point and negative to the right of the MPP. Mathematical of the Inc.Cond algorithm is discussed below.
The derivative of output power is:

$$
\begin{aligned}
& \frac{\mathrm{dP}}{\mathrm{dV}}=\mathrm{V} \frac{\mathrm{dI}}{\mathrm{dV}}+\mathrm{I}=0 \\
& \therefore \frac{d I}{d V}=-\frac{I}{V}
\end{aligned}
$$

This leads to the following set of equations:

$$
\begin{aligned}
& \frac{d P}{d V}>0 \text { at the left of MPP } \\
& \frac{d P}{d V}=0 \text { at MPP } \\
& \frac{d P}{d V}<0 \text { at the right of MPP }
\end{aligned}
$$

Figure 9, illustrate the flowchart of Inc-Cond methods.

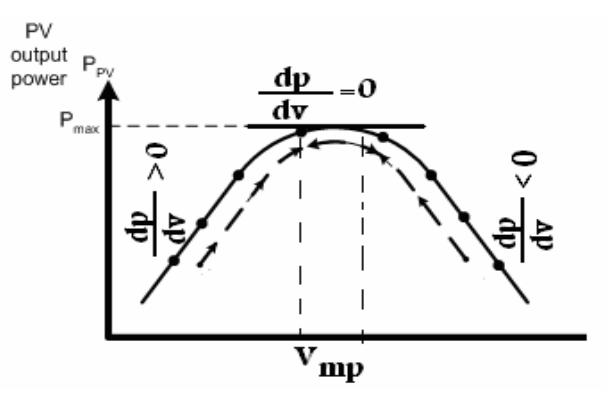

Fig. 8. PV characteristic of PV panel

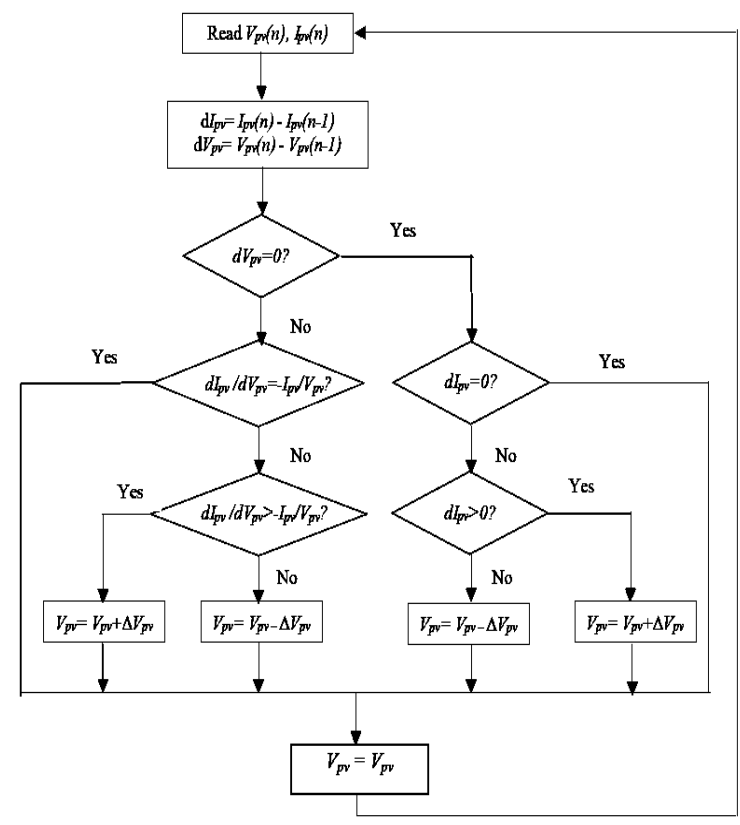

Fig. 9. Flow chart of Inc. Con. algorithm

\subsubsection{Power Measurement Method (Power Derivation )}

By measuring the panel voltage and current, the PV panel output power is calculated and compared to previous PV output power. Depending on the result of the comparison, the duty cycle is changed accordingly and the process is repeated until the maximum power point has been reached. The MMP tracking process is shown in Fig. 10 and the flowchart of this method shows in Fig. 11. 


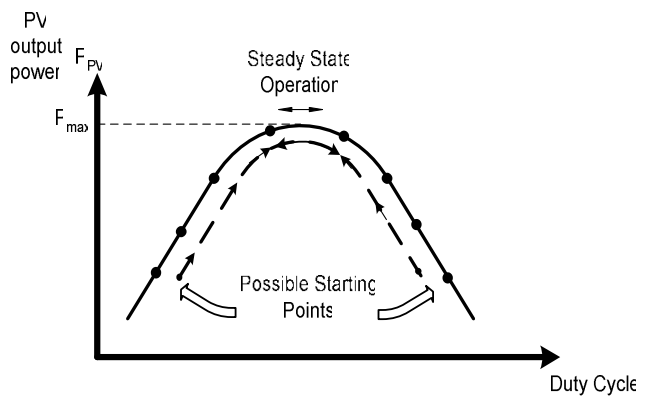

Fig. 10. MMP tracking process

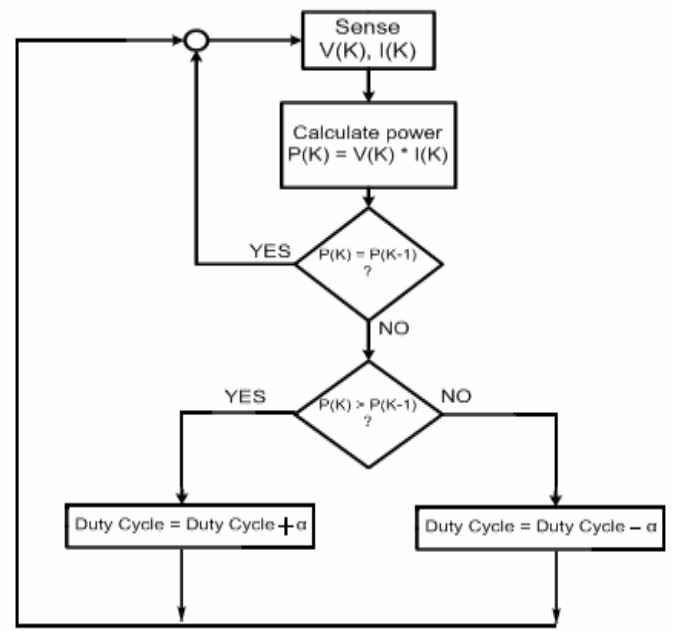

Fig. 11. MPPT control flowchart of measure PV power method, $(\alpha$, step of duty cycle $)$

\section{EXPERIMENTAL RESULTS}

\subsection{Evaluation of Boost Converter}

This converter is capable of delivering most of the input power from P.V. panel to the load. The following results show the behavior to the boost converter under different switching frequency and duty cycle ratios that could affect the power efficiency of the boost converter. Figure 12 shows the practical obtained relation between the switching frequency $(\mathrm{Hz})$ and the booster output power efficiency. The duty ratio was set and kept constant at $50 \%$. The input of converter is the P.V. panel output. The input and output power are recorded under various switching frequency. Then, the switching frequency is kept constant at $3 \mathrm{KHz}$ (optimum frequency found in Fig. 12 ) and the duty cycle is varied while the power efficiency $\left(\mathrm{P}_{\text {out }} / \mathrm{P}_{\text {in }}\right)$ is recorded and represented as shown in Fig. 13.

\subsection{Testing the MPPT Algorithms}

In order to demonstrate the effectiveness of the maximum power tracking algorithm and to show how to extract the maximum power from the PV generator, the strategy used in the presented paper consists of the following steps.
1. Study the operation of the PV generator with direct connection of the load (without MPPT controller or without load conditioner) for a certain period of time.

2. After a certain time determined in (1), let the controller operate and the MPPT algorithm control the operation and force the PV generator to operate in its maximum power point.

When the above strategy is applied it is very simple to note the difference between the case of direct connection and the case of conditioned connection where the power difference is very large and clear, so the main goal of MPPT algorithm is satisfied. This strategy is applied for the three methods considered in this paper under different value of radiation and constant load. Figures 14, 15 show the practically results of panel power when the $\mathrm{P} \& \mathrm{O}$ algorithm is applied with respect to time and panel voltage respectively. Than the Inc. Cond. algorithm is applied and it gives the practically results that illustrated in Figs 16 and 17 of the panel power verses time and panel voltage respectively.

While, the practically results of third method of MPPT algorithm applied in this paper (Power Derivation Algorithm) are illustrated in Figs. 18 and 19.

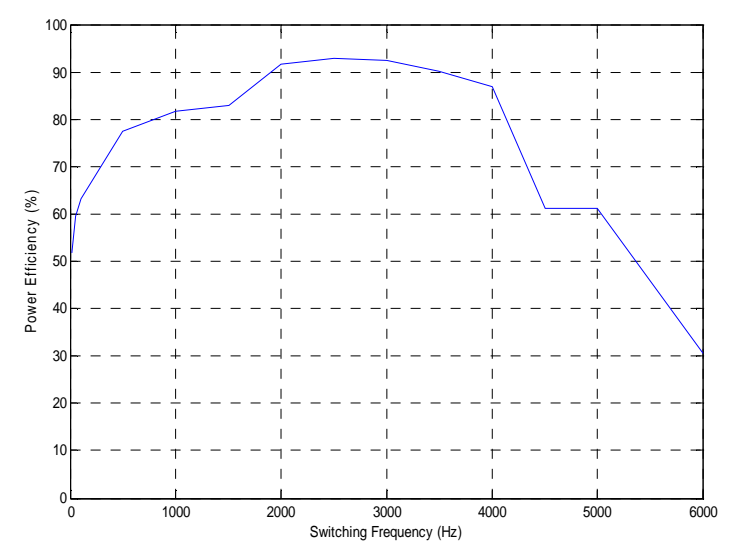

Fig. 12. Power efficiency of the converter vs switching frequency

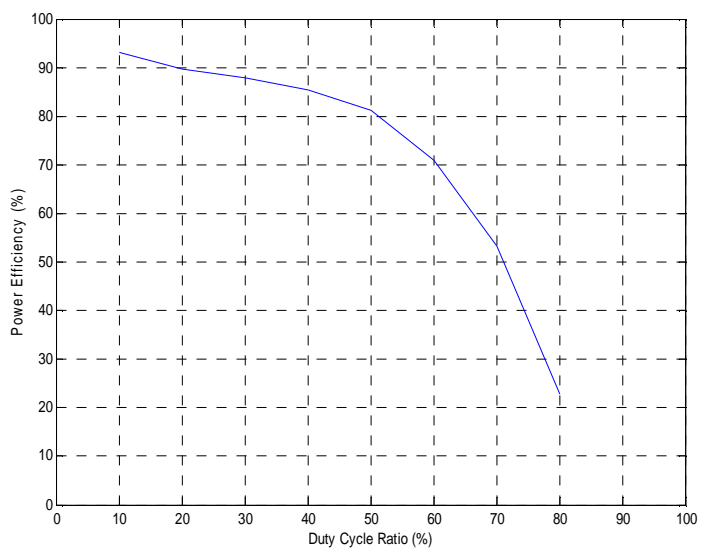

Fig. 13. Power efficiency of the converter vs. duty cycle 


\subsection{Long Run System Operation}

In order to demonstrate the reliability of the controller, the system is executed for long time and the practically results are obtained for different algorithms. Figure 20 show the results for Perturbation and observation algorithm. Figure 21 demonstrate the results for the second algorithm (Inc.Cond algorithm), while Fig. 22 shows the results for power derivation algorithm.

Finally, Fig. 23 shows the results of the three different algorithms at the same chart.

\section{CONCLUSION}

The presented paper introduced the design and practical implementation of the computer-based maximum power point tracker to allow the transfer of maximum energy generated by photovoltaic panel to the load. The main goal of this work is to increase the efficiency in comparison to systems have no MPPT, and thus to reduce the size and cost of the PV panel. To demonstrate the effectiveness of the MPPT control, the load is first connected directly to the panel without MPPT controller of a certain time and then a controller is applied, in this last case, the power obtained from the panel increased and the panel operated in its maximum power.

The computer is used to fulfill three goals namely, system variables monitoring, measuring device, and the mainly controller.

Three methods of MPPT control algorithms are applied (P\&O, Inc-Cond, and Power derivation), the obtained results are almost the same but there are some differences in the response time. We considered that the power derivation as algorithm simple in implementation and gives more stable results than others.

From all results, its clear that, the performance of system under conditioner is much better than the direct connection, the change of operating voltage is not large when the radiation is changed, the response system under MPPT control is satisfactory when it operates under random environmental conditions (clear and largely cloudy day), and the operating point of the panel always operates around the MPP as radiation varies. All these results demonstrate that the MPPT controller dominates the dynamic behavior of the PV power generation.

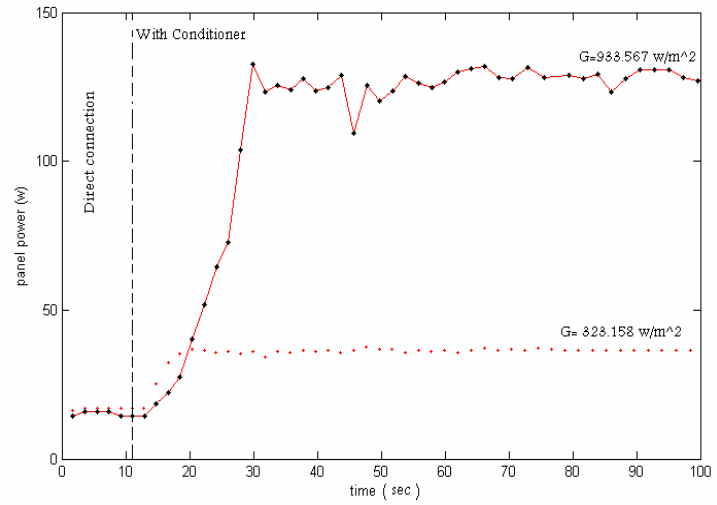

Fig. 14. panel power vs. time at $\mathrm{G}=933.567 \mathrm{~W} / \mathrm{m}^{2}$ and $323.158 \mathrm{~W} / \mathrm{m}^{2}, \mathrm{R}_{\mathrm{L}}=700 \Omega$ applying $\mathrm{P} \& \mathrm{O}$ algorithm.

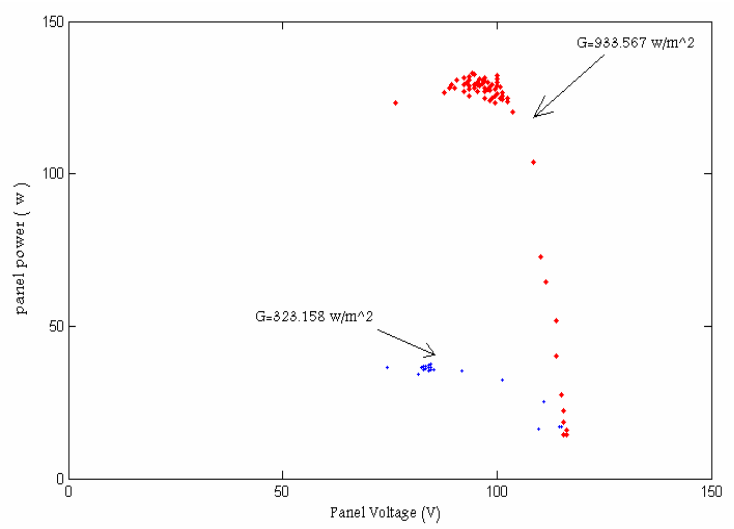

Fig. 15. $\mathrm{P}_{\mathrm{pv}}$ vs. $\mathrm{V}_{\mathrm{pv}}$ curve applying $\mathrm{P} \& \mathrm{O}$ algorithm

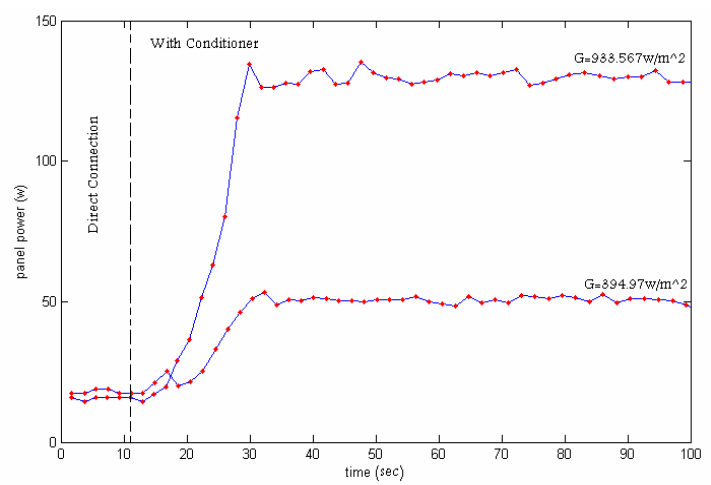

Fig. 16. Panel power at $\mathrm{G}=933.567 \mathrm{w} / \mathrm{m}^{2}$ and 394.67 $\mathrm{w} / \mathrm{m}^{2}, \mathrm{R}_{\mathrm{L}}=700 \Omega$ using Inc. Cond. Method 
Adel A. Abosnina, Mahmoud Shaker, "Design and Implementation of Digitally Controlled Photovoltaic ..."

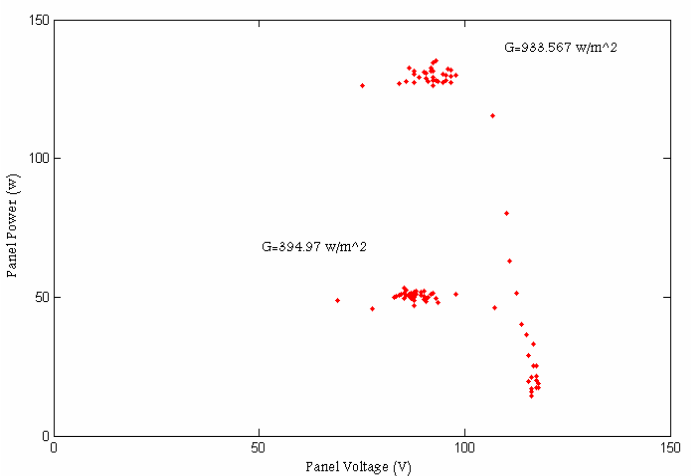

Fig. 17. Panel power vs. Voltage at $\mathrm{G}=933.567 \mathrm{w} / \mathrm{m}^{2}$ and $394.67 \mathrm{w} / \mathrm{m}^{2}, \mathrm{R}_{\mathrm{L}}=700 \Omega$ using Inc. Cond. Method.

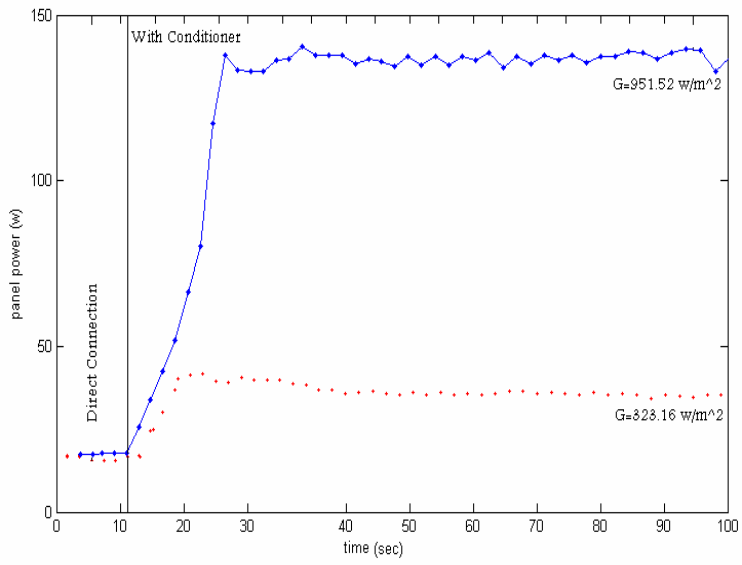

Fig. 18 panel power vs. time at $\mathrm{R}_{\mathrm{L}}=700 \Omega$ and $\mathrm{G}=951.52 \mathrm{w} / \mathrm{m}^{2}, 323.16 \mathrm{w} / \mathrm{m}^{2}$ using Power Derivation Algorithm.

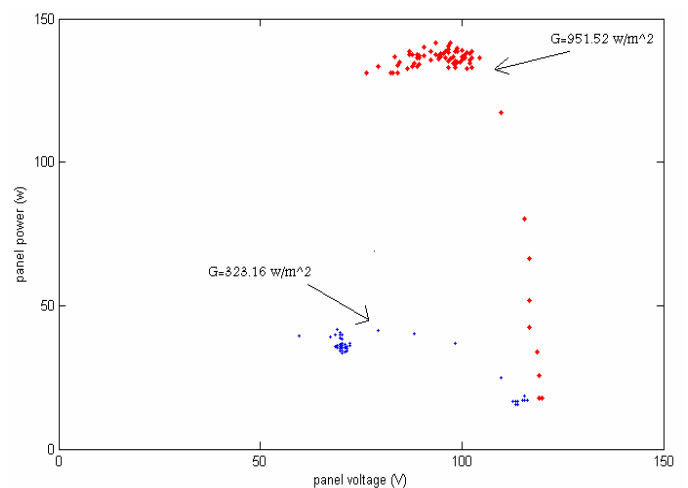

Fig. 19. $P_{p v}$ vs. $V_{p v}$ curve using Power Derivation Algorithm..

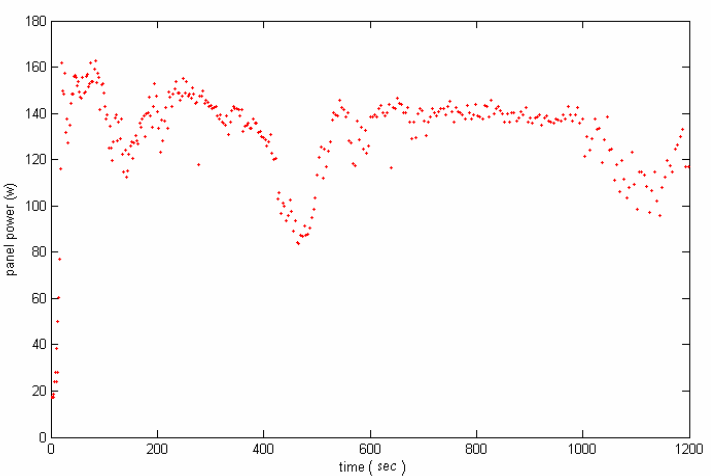

Fig. 20. Long time run of Power vs. time (Perturbation and observation algorithm)

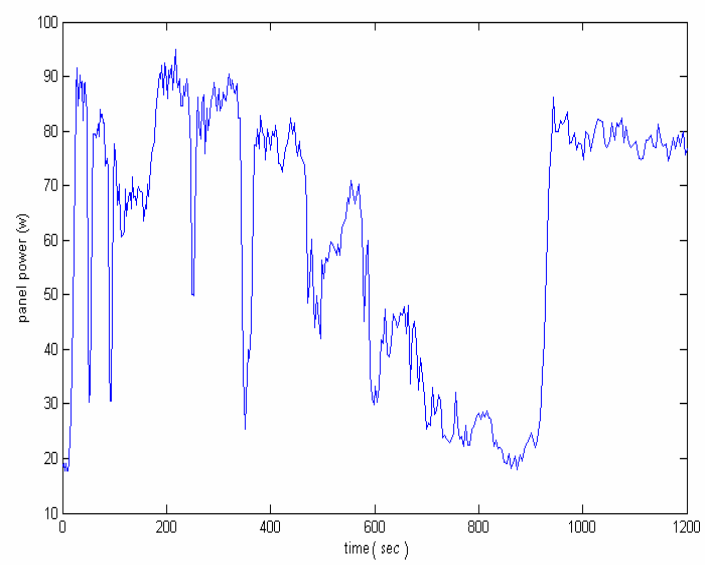

Fig. 21. Long time run of Power vs. time. (Inc.Cond algorithm)

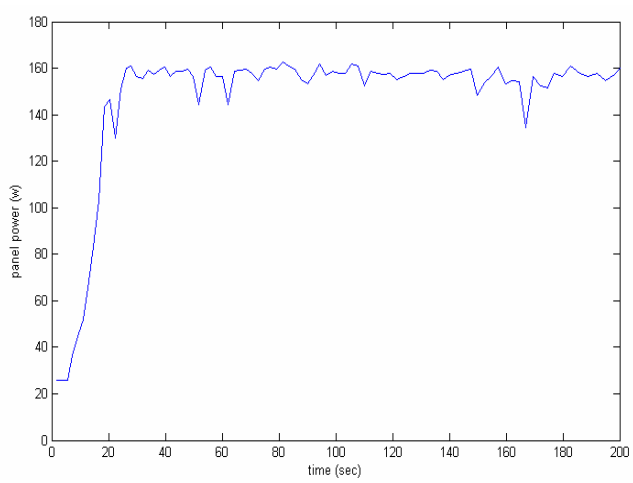

Fig. 22. Long time run of Power vs. time. (power derivation algorithm) 


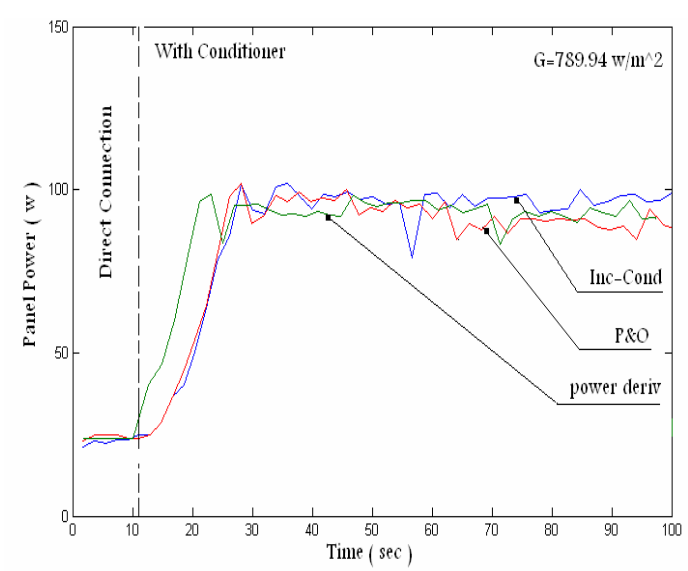

Fig. 23. Comparison between control algorithms at $\mathrm{G}=789.94 \mathrm{w} / \mathrm{m}^{2}$ and $\mathrm{R}_{\mathrm{L}}=500 \Omega$

\section{REFERENCES}

[1] Hannes Knopf, "Analysis, Simulation, and Evaluation of Maximum Power Point Tracking (MPPT) Methods for a Solar Powered Vehicle ", Msc Thesis, Portland State University, 1999.

[2] M. Jantsch1, M. Real, H. Häberlin, C. Whitaker, K. Kurokawa, G. Blässer, P. Kremer, and C.W.G. Verhoeve, "Measurement of PV Maximum Power Point Tracking Performance ", 14th EUPVSEC 1997.

[3] Ashraf Abdel Hafeez, Khaled El-Metwally, and Osama Mahgoub, "A Photovoltaic Intelligent Power Conditioning Unit for MPPT Using Neural Networks ", 5th International Engineering Conference, No 205, 2006.
[4] Yun Tiam Tan, "Impact on The Power System with A Large Penetration of Photovoltaic Generation", phd dissertation, Manchester Institute University, 2004.

[5] Richard A. Cullen President Blue Sky Energy, Inc. "What Is Maximum Power Point Tracking (MPPT) and How Does It Work"

[6] S. Armstrong, W.G. Hurley, "Self-Regulating Maximum Power Point Tracking for Solar Energy Systems ", NUI, Galway Faculty of Engineering Research Day, 2004.

[7] Eftichios Koutroulis, Kostas Kalaitzakis, and Nicholas C. Voulgaris, "Development of A Microcontroller- Based, Photovoltaic Maximum Power Point Tracking Control System ", IEEE Transactions on Power Electronics, Vol. 16, No. 1, 2001.

[8] Masafumi Miyatake, Tooru Kouno, and Motomu Nakano, "A Simple Maximum Power Point Tracking Control Employing Fibonacci Search Algorithm for Power Conditioner of Photovoltaic Generators ", EPE-PEMC 2002.

[9] Mahmoud Sh., Hassan A., Adel A. " Micro Controller- based, Photovoltaic Maximum Power Point Tracking", M.Sc. thesis, college of engineering, university of garyounis, 2007.

[10] Adel A. Abosnina, and Mahmoud Shaker, " Solar Radiation Study in Benghazi City and Modeling, Experimental Verification of A PV panel", ERJ, Vol. 32, No. 3, 2009. 